\title{
Urban Green Space Desirability Assessment, Environmental Justice: An Approach in cities Planning Towards Making Cities Sustainable
}

\author{
NedaOrak ${ }^{1}$, Kamran Zandvakili ${ }^{2}$, \\ Sina Attar Roshan ${ }^{3}$ and Fariba Babaei Abkenar ${ }^{4}$
}

\begin{abstract}
:
Cities planning have been lead to constructions with no attention on hygienic necessities especially in dense areas. Creating new land uses is necessity to response the urban needs and residents and resulted in green spaces decrease. It caused environmental pollutions. Attention to environmental problems has increased in urban development progresses. Sustainable, healthy and green cities formations are derived from environmental concepts. Parks have strategic importance to life conditions improvement. In addition to existence, desirability is considerable. This research has been done with the aim of Ahwaz green space desirability assessment which is 3rd IRAN extensive city. Desirability Indices have been selected as economic, social, safety and environmental from people and experts point of view. Assessment criteria are: proximity to rivers, residential, educational centers, facilities and equipments, cultural centers, compatibility to landuses, access to communication nets, high population density and percapita green spaces. Research statistical societies are 384 citizenry and 30 experts. Different indices were weighted by Expert Choice software in AHP model. Regions classification done in 5 categories by data layers overlying in GIS as: very good to inappropriate. Social utility to green spaces improvement with 0.300 score in priority according to experts. Safety is preferred in accordance to citizenry and T model (0.603). All 4 areas except no. 3 have deficiency. Center toward west has the best conditions to develop. These results can help planners significantly to understand, prioritize and solve cities problems.
\end{abstract}

Keywords: AHP model, Abwaz, GIS, Green space locating, place desirability

\section{Introduction:}

According to rapid urbanization growth, it is expected $65 \%$ of world population will live in cities until 2025. It will be 70\% until 2030 (Amanpoor\&Alizadeh, 2013). Direct results of increased population are includes: Increased congestion, construction densities without attention to aesthetics and urban comfort. Subsequently, water, air and noise pollution will be in cities. Since green spaces are as earth lungs, attention to their quantity and distribution is basic necessity to a sustain planning (Gupta et al., 2012). Urban green areas have more values in dense cities nowadays. There is a worry on the shortage due to all lands used to increasing housing (Rafiee, 2009). There is another subject: attention to green spaces is considered as a basis to cities sustainability and sustainable designing. Green and compact cities are from sustainability models. Those

${ }^{1}$ Assistant Professor, Department of Environmental Science, College of the agriculture and natural resources, Ahvaz Branch, Islamic Azad University, Ahvaz, IRAN.

2 Water and Power Authority, IRAN

${ }^{3}$ Assistant Professor, Department of Environmental Science, College of the agriculture and natural resources, Ahvaz Branch, Islamic Azad University, Ahvaz, IRAN,

${ }^{4} \mathrm{MSc}$. Graduated, Department of Environmental Science, College of the agriculture and natural resources, Ahvaz Branch, Islamic Azad University, Ahvaz, IRAN. 
and even smart cities and smart urban growth are indices of urban green spaces in all intellectual foundations (Kabisch\&Hasse 2013). Green spaces proper distribution is of the main challenges in relation to creating and existence, especially in developing countries (Lotfi et al., 2012).

Wrong urban spaces location will caused anomalies such as: users underutilization, proper architectural presentation limitations, limited flora selection and layout, turmoil in city face, irrigation and soil improvement, lack of appropriate interactions, management and maintenance, social and Psychological security reduction, etc. (Rahmani, 1994).

Special attention to walking and green transportation beside urban green spaces and the uses are of the basic solutions in successful urban planning in developing countries, nowadays (Ziari et al., 2010). It is clear environmental concepts consideration and cities improvement such as parks and green areas care had been emphasized after sustainable development idea. According to importance of topic, Ahvaz metropolis has been selected to spatial desirability assessment. Ahvaz and its regions can provide a good background to research and green spaces assessment because of urban density, sultry weather, rare climatic phenomena such as dusts, urban green spaces asymmetric distribution especially parks, life quality and social welfare consideration, social interactions strengthening more than before, landscapes smarten up.

Since health, beauty and comfort are cities programming main objects, so urban green spaces locating is one of the most important cities environmental elements. It has main role to desirability and pleasance by citizenries. So, this research ultimate goals are as follow:

- Parks locating effective factors determination. How combination in GIS to suitable pattern creation.

- East of Ahvaz metropolis data layers identification and classification. Green spaces Land uses proximity priorities by experts.

- Recognition urban green spaces optimal zone establishment.

Several researches and studies have been done on urban green spaces due to matter importance. Some of the newest are: Orak et al., 2014, Ziari et al. 2014, Ajzashokoohi et al. 2013 in IRAN and Lee et al., 2014, Van zoest\&Hopman 2014, Kaetano 2014, Balooni 2014 in the world. GIS, satellite images and statistical analysis have been used to parks influence for sustainable cities, healthy environment, positive effects to residuals mental and municipal top designs in all researches.

\section{Material and methods}

Needed data have been gathered by observation, descriptive- analytical methods. Descriptive data entered to data banks. Overlay, spatial analysis, proximity are applied to suitable location analysis. Weighted overlay has been used to parks optimal zone identification. Data retrieval, classification, analysis, remove and add is possible too. Output will be suitable locations to urban parks develop map. AHP model were employed to experts opinions by expert choice. Obtained weights were incorporated to final map. Fig.1 indicates research model. 


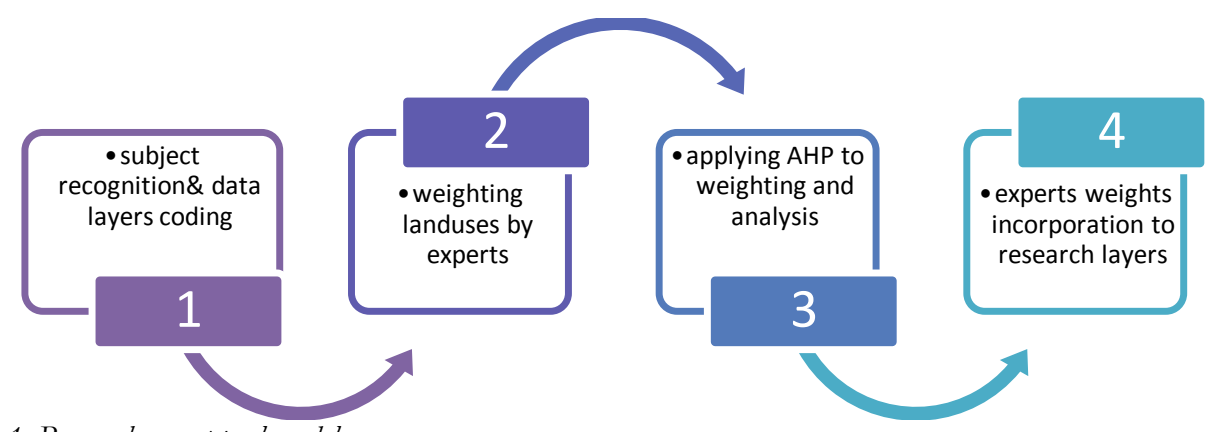

Fig. 1. Research conceptual model

\subsection{Study Area}

Ahvaz is third extensive city of IRAN. It is located between $30^{\circ} 23^{\prime}$ to $31^{\circ} 13^{\prime} \mathrm{N}$ and $48^{\circ} 23^{\prime}$ to $48^{\circ} 47^{\prime} \mathrm{E}$. Total area is about 31800 hectares. Karoon River divides city into 2 eastern and western parts. Eastern includes 4 regions $(1,3,7,8)$. This research focuses on eastern part because on the it's vastness. Fig. 2 shows the situation and tab. 1 population and area.

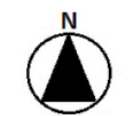

$1: 35000 \mathrm{~m}$

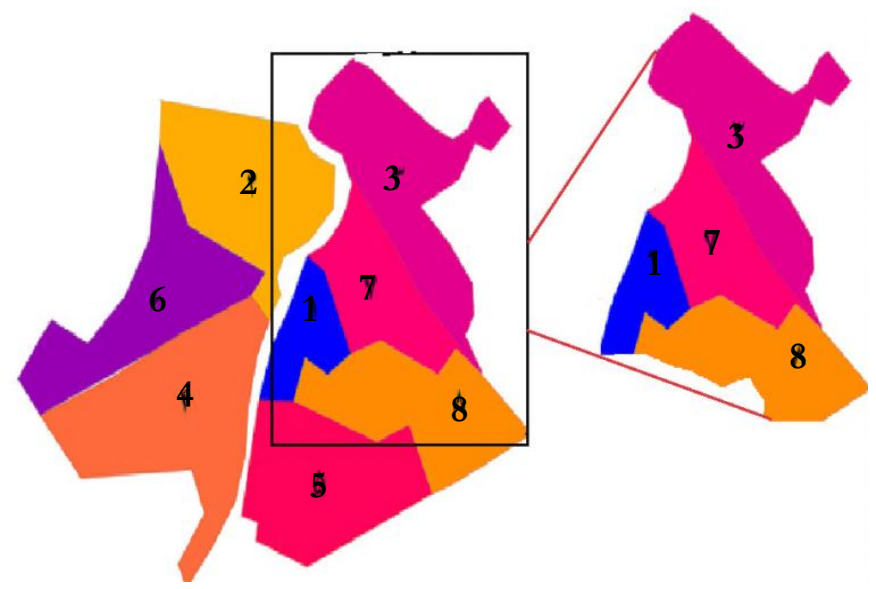

Fig. 2 Study area regions geographical location in east of Abvar. 
Table 1. Population and Urban green space in East of Ahvaz

\begin{tabular}{|c|c|c|c|c|c|c|}
\hline Region & $\begin{array}{l}\text { Population } \\
\text { (person) }\end{array}$ & $\begin{array}{l}\text { Per capita } \\
\qquad\left(\mathrm{m}^{2}\right)\end{array}$ & $\begin{array}{l}\text { Area } \\
\left(\mathrm{m}^{2}\right)\end{array}$ & Land use & $\begin{array}{l}\text { Green } \\
\text { Area }\left(\mathrm{m}^{2}\right)\end{array}$ & $\begin{array}{l}\text { space } \\
\text { ) } *\end{array}$ \\
\hline 1 & 128893 & 3.31 & 3758707.47 & Green space\&park & 83 & 4900 \\
\hline 3 & 165688 & 9.23 & 6334992.73 & Green space\&park & 260 & 3296 \\
\hline 7 & 162352 & 3.15 & 3998415.05 & Green space\&park & 94 & 5610 \\
\hline 8 & 118615 & 6.86 & 4119691.91 & Green space\&park & 51 & 3123 \\
\hline
\end{tabular}

Includes: district parks, region parks, zone parks, neighborhood parks.

\section{Results:}

Data layers were formed. Buffering were done to land uses layers integration and standardization. It was done in accordance to represented spatial standards by Urbanism and Architecture Council (tab. 2). Spatial and layers evaluating were applied in ArcGIS by reclassify.

Tab. 2 land uses spatial $\&$ distance standards

\begin{tabular}{|c|c|c|c|}
\hline Land use & $\begin{array}{l}\text { Standard } \\
\text { distance }(\mathrm{m})\end{array}$ & Land use & $\begin{array}{l}\text { Standard } \\
\text { distance }(\mathrm{m})\end{array}$ \\
\hline Residential & 150 & Education & 150 \\
\hline Commercial & 150 & Military & $1000-500$ \\
\hline Hygiene & 150 & Fueling & $150-500$ \\
\hline Administrative & 150 & Links \& Ways & $150-500$ \\
\hline Cultural & 150 & Fire station & $150-500$ \\
\hline Sport & $150-500$ & \multirow[t]{2}{*}{ Terminal } & $150-500$ \\
\hline Industrial & $500-1000$ & & \\
\hline
\end{tabular}

Neighborhood land uses adaptability and conflicts by urban parks is important subject beside standardized values. It can help desirable green spaces establishment in relation to distances. Evaluating justification will be more clear.

Expert survey is the next step. Final weights will be evaluated in order to land uses layers integration. It will be for final values and spatial green spaces recognition in east of Ahvaz. Fig. 3 shows weighted diagram according to AHP model. 


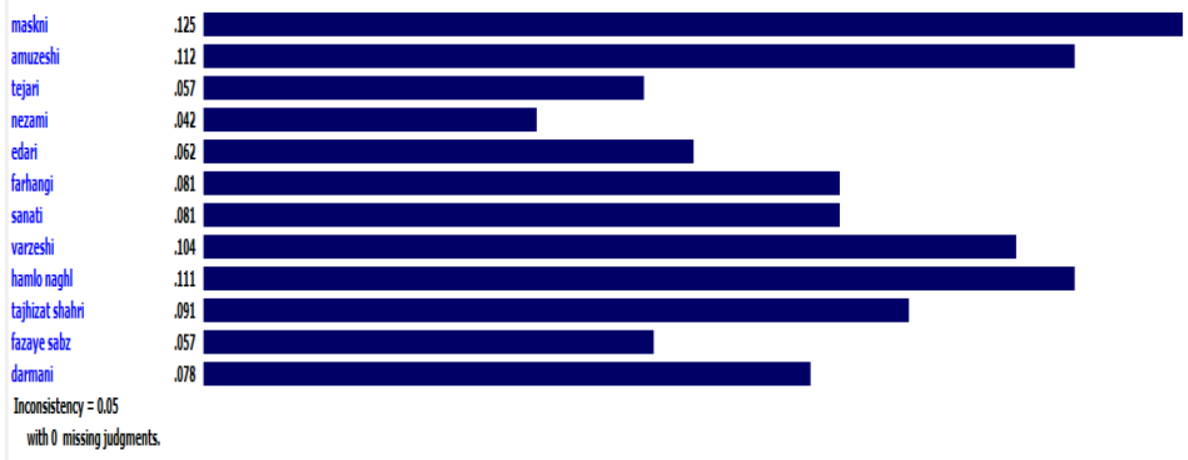

Fig. 3 Experts weighting results by AHP and Expert choice

Obtained weights show residential areas have high score (0.125). It is the first priority. The last green spaces capability map zoning produced by combination expert analysis results to final plan. Fig. 4 shows the final map for Ahvaz.

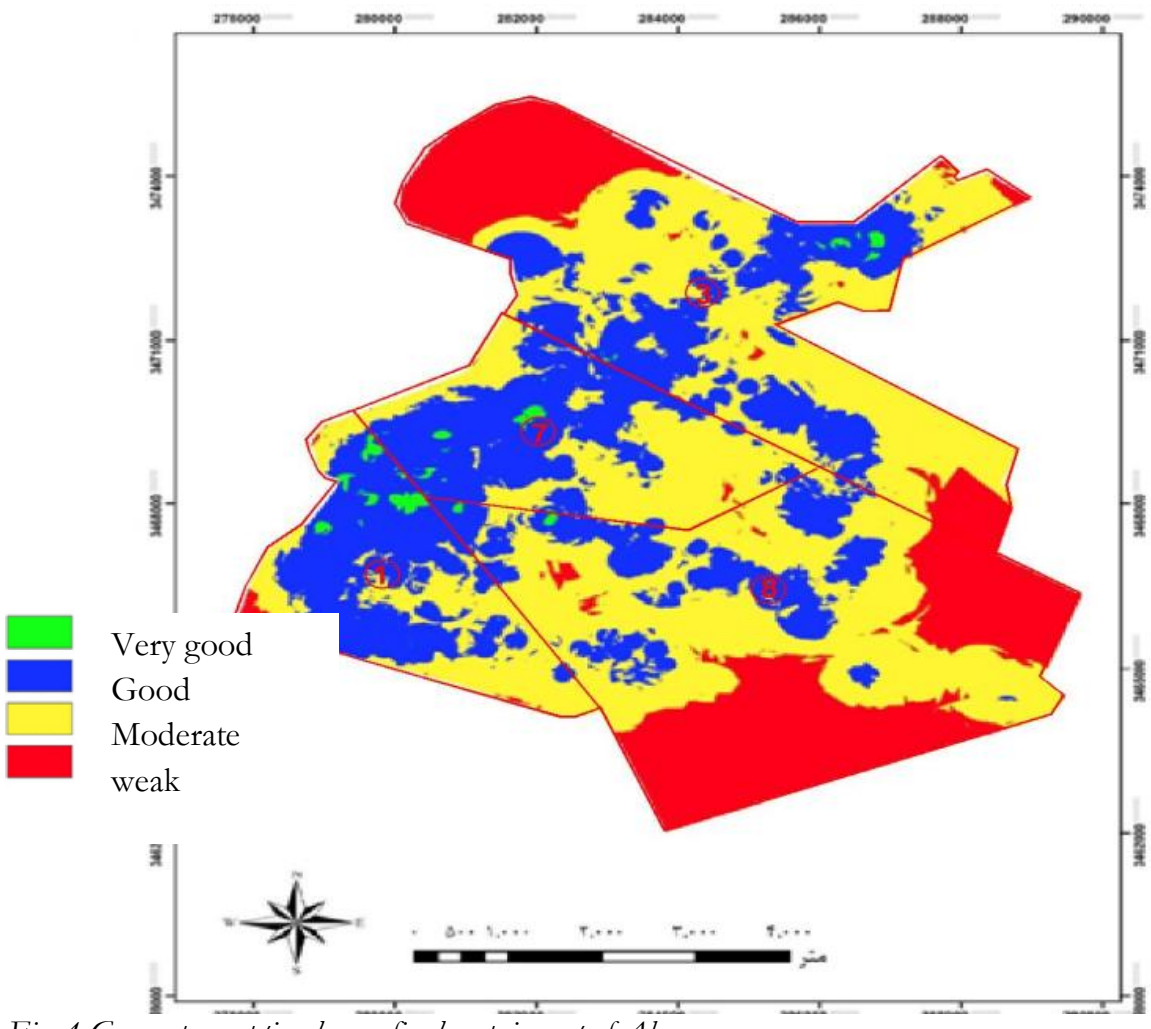

Fig. 4 Green space optimal zone final map in east of Ahvar. 
4 green spaces levels can be seen on ma as it seen in fig.4. The most capability can be seen in region No.7. The least is for No. 8.

Results show central parts towards west have the best desirability and so capability to parks establishment. Desirability will diminished how much it goes to south and south east from center and west. East and south east are not suitable. Desirability is low. Tab. 3 shows the research indices in 4 desirability categories.

Table 3. Research indices in residential views

\begin{tabular}{|c|c|}
\hline Indices & Variables \\
\hline Economic Desirability & $\begin{array}{l}\text { Total costs- land located price- resources consumption land } \\
\text { funding/ finance }\end{array}$ \\
\hline Social Desirability & $\begin{array}{l}\text { Residential access- quantity and distribution in region- facilities } \\
\text { for disabled- recreational opportunities- access by distance and } \\
\text { time }\end{array}$ \\
\hline $\begin{array}{l}\text { Environmental } \\
\text { Desirability }\end{array}$ & $\begin{array}{l}\text { Parks flora type- site selection Desirability- pollution reduction } \\
\text { by suitable site selection- noise pollution and traffic control- } \\
\text { clean environment }\end{array}$ \\
\hline Safety Desirability & $\begin{array}{l}\text { Safety by type of designing- lighting- night view- adaptive land } \\
\text { uses neighborhood- suitable for ladies and kids- access to rescue } \\
\text { centers }\end{array}$ \\
\hline
\end{tabular}

384 persons were questioned in ratio to every region population. Residential views analysis showed: - land located price by 2.78 score in economic desirability is the highest. Finance is the lowest, too.

In social part, access has the most amount by 2.66 and disables facilities by 1.91 is the least. Cleanness and freshness is the most important by 2.98 scores and the least one is flora type by 2.44 in environmental desirability.

Access to rescue centers is the best by 2.56 scores in safety part. Type of designing is the weakest by 2.29. Fig. 5 shows mean deviation in different indices to eastern part of Ahvaz. Fig. 5 shows mean deviation in different indices to eastern part of Ahvaz. 


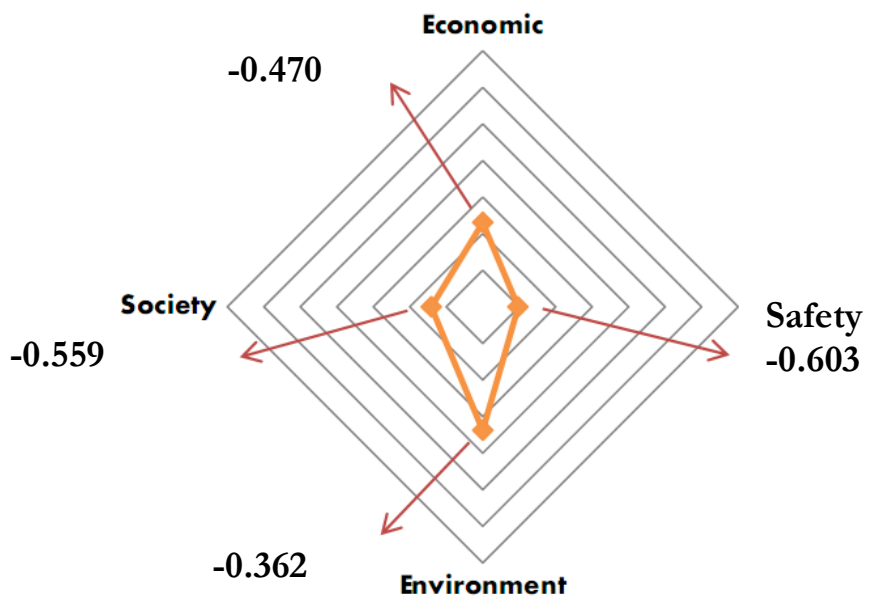

Fig. 5 Difference of desirability indices mean to east Ahvazparks

According to fig. 5 safety desirability has unsuitable situation with less mean deviation (0.603). It means this is the first citizenries request to have a pleasant park. Also, Other indices by negative deviation emphasis on inappropriate conditions. Expert analysis showed the same results, too.

\section{Discussion:}

There are critical conditions in 21 th century because of urban population increase and metropolises forming. Attention to environment elements is necessary more than before. Sustainability must be the $1^{\text {st }}$ priority if human is interested to be on modernity. Modern approaches in structures and outspread constructions caused environmental pressures increase. So attention to suitable concepts and green zones are essential especially in current decay. This research showed central parts have the best quality to parks establishment.

Different regions comparison based on ministry standards shows best conditions is current in region 3. Region No.7 has is the least. Investigation on people income show a coordination too

\section{Recommendation:}

Encourage investors to rebuilding parks

Building bigger parks with more facilities

Designing parks in accordance to international parks criteria

Raising people awareness in optimal uses

Employing green spaces managers and professional experts to decision making

Green spaces characteristics and problems identification in Ahvaz 


\section{Acknowledgement:}

It is necessary to be thanked of Islamic Azad University Ahvaz branch. This manuscripts is presented by Islamic Azad University Ahvaz branch supports. I must be thankful of Ahvaz municipality to do the research.

\section{References:}

Ajzashokoohi, A., KazemiKhabiri, Kh.,Hossein Poor, S.A., (2013) urban green space strategic programming with emphasis on sustainable development in Mashad region, Landscape architecture journal. No.1

Aman poor, S., Alizadeh, H., (2013) Evaluation of sustainable development indices in Kermanshah By Regression Analysis and AHP. Geography and municipal and regional landuse planning journal. No.9

Caetano. M (2014) Effects of green space spatial pattern on land surface temperature: Implications for sustainable urban planning and climate change adaptation. SPRS Journal of Photogrammetry and Remote Sensing, Volume 89, March 2014, Pages 59-66

Gupta, K., Kumar, P., Pathan, S.K., \& Sharma, K.P. (2012) Urban Neighborhood Green Index - A measure of green spaces in urban areas, Landscape and Urban Planning, 105, 325-335.

Gupta, K., Kumar, P., Pathan, S.K., \& Sharma, K.P. ,2012, Urban Neighborhood Green Index - A measure of green spaces in urban areas, Landscape and Urban Planning, 52(13), 325-335.

Caetano. M (2014) Effects of green space spatial pattern on land surface temperature: Implications for sustainable urban planning and climate change adaptation. SPRS Journal of Photogrammetry and Remote Sensing, Volume 89, March 2014, Pages 59-66

Gupta, K., Kumar, P., Pathan, S.K., \& Sharma, K.P. (2012) Urban Neighborhood Green Index - A measure of green spaces in urban areas, Landscape and Urban Planning, 105, 325-335.

Gupta, K., Kumar, P., Pathan, S.K., \& Sharma, K.P. ,2012, Urban Neighborhood Green Index - A measure of green spaces in urban areas, Landscape and Urban Planning, 52(13), 325-335.

Kabisch. N, Qureshi. S and Dagmar Haase(2015) Human-environment interactions in urban green spaces - A systematic review of contemporary issues and prospects for future research. Environmental Impact Assessment Review, Volume 50,pp. 25-34

Lee, So Young Sohn, SeungheeYang(2014) Design guidelines for the Dashilar, Beijing Open Green Space Redevelopment Project. Urban Forestry \& Urban Greening, In Press, Corrected Proof, Available online 10 January 2014

Orak, N., Babaei, F., Attar roshan, S., (2014) Green space Desirability assessment in east of Ahvaz by AHP and GIS. Islamic Azad University Ahvaz Branch.

Rafiee, R., Mahiny, A.S., \&Khorasani, N(2009) Assessment of changes in urban green spaces of Mashad city using satellite data, International Journal of Applied Earth Observation and Geoinformation, 11, 431-438.

Rahmani, M., (1993), investigation on decision making procedure in parks locating, influence on safety. Sabzineh Journal, No.6

Ziarri, k., Mahdnejad, H., Parhiz, F., (2010) municipal programming principles and techniques, Chabahar University, 1stEddition 